\title{
HUBUNGAN PENGETAHUAN ORANG TUA TENTANG STIMULASI DENGAN PERKEMBANGAN MOTORIK HALUS ANAK PRA SEKOLAH
}

\author{
Nova Gerungan \\ Fakultas Keperawatan Universitas Klabat Airmadidi \\ Email:nova.gerungan@unklab.ac.id
}

\begin{abstract}
ABSTRAK
Stimulasi merupakan satu kegiatan untuk merangsang kemampuan dasar anak, kegiatan ini dapat dilakukan orang tua dengan mengajak anak bermain bersama yang dilandasi dengan cinta dan kasih sayang. Anak memiliki suatu ciri yang khas yaitu bertumbuh dan berkembang dan setiap anak akan melewati proses tumbuh kembang sesuai dengan tahapan usianya. Perkembangan yang terjadi tentunya akan menimbulkan perubahan pada anak. Orang tua berperan penting dalam proses perkembangan anak, karena menjadi tanggung jawab orang tua untuk memberikan stimulasi. Kurangnya stimulasi dapat menyebabkan penyimpangan tumbuh kembang anak bahkan gangguan yang menetap. Salah satu penyebab masalah perkembangan anak adalah karena kurangnya pengetahuan orang tua mengenai cara memberikan stimulasi. Tujuan penelitian ini adalah untuk mengetahui hubungan pengetahuan orang tua tentang stimulasi dengan perkembangan motorik halus anak pra sekolah. Desain penelitian menggunakan deskriptif korelasi dengan pendekatan cross sectional, pengambilan sampel dengan cara purposive sampling sebanyak 46 orang tua dan anaknya yang berusia pra sekolah. Instrument penelitian menggunakan kuesioner pengetahuan orang tua tentang stimulasi dengan Kuesioner Pra Skrining Perkembangan (KPSP) dan uji statistik menggunakan spearman rank. Hasil penelitian yaitu tidak terdapat hubungan signifikan pengetahuan orang tua tentang stimulasi dengan perkembangan motorik halus anak pra sekolah $p$ value $=0,06>0,05$. Sebagai rekomendasi bagi tenaga kesehatan agar dapat melakukan penyuluhan kepada masyarakat mengenai pentingnya melakukan stimulasi untuk membantu meningkatkan keterlibatan keluarga khususnya orang tua dalam memberikan stimulasi.
\end{abstract}

Kata kunci: Anak pra sekolah, Perkembangan motorik halus, Stimulasi

\section{ABSTRACT}

Stimulation is an activity to stimulate children's basic abilities. Parents can stimulate their children by playing together with love and affection. Children have a characteristic that is growing and developing and each child will go through the process of growth and development according to the stages of his age. The developments that occur will certainly lead to changes in children. Parents play an important role in the child's development process, because it is the responsibility of parents to give stimulation. Lack of stimulation can cause deviations in child development and even permanent disturbances. One of the causes of child development problems is due to a lack of parental knowledge about how to give stimulation. The purpose of this study was to determine the relationship of parental knowledge about stimulation with fine motorik development in pre-school children. The study design used descriptive correlation with cross sectional approach, sampling by purposive sampling as many as 46 parents and children aged pre-school. The research instrument used a parent knowledge questionnaire about stimulation with the Kuesioner Pra Skrining Perkembangan (KPSP) and statistical tests using rank spearman. The results of the study found that there is no significant relationship of parental knowledge about stimulation with fine motorik development in pre-school children $p$ value $=0.06>0.05$. As a recommendation for health 
workers is to educate the public about the importance of stimulating to increase family involvement, especially parents in giving a stimulation.

Keywords: Pre-school children, Fine motorik development, Stimulation

\section{PENDAHULUAN}

Anak memiliki ciri khas yaitu bertumbuh dan berkembang yang dimulai sejak konsepsi sampai akhir masa remaja. Pertumbuhan berarti terjadinya penambahan ukuran fisik dan struktur tubuh, sedangkan perkembangan adalah bertambahnya kemampuan motorik kasar, motorik halus, kemampuan bicara dan bahasa serta kemampuan sosialisasi dan kemandirian anak (KEMENKES RI, 2010).

Periode prasekolah adalah antara usia 3 sampai 6 tahun, pada tahap usia ini merupakan kelanjutan pertumbuhan dan perkembangan anak dimana pertumbuhan fisik akan menjadi lebih lambat dari tahun sebelumnya dan terjadi peningkatan pada perkembangan kognitif, bahasa dan psikososial (Kyle \& Carman, 2013).

Penting bagi seorang anak untuk mendapatkan stimulasi yang tepat agar dapat tumbuh dan berkembang dengan baik. Periode penting untuk memberikan stimulasi adalah pada usia balita, karena pada tahap usia ini anak akan mengalami pertumbuhan dan perkembangan yang sangat cepat. Kurangnya stimulasi yang diberikan dapat mempengaruhi perkembangan anak pada tahap usia selanjutnya (Potts \& Mandleco, 2012).

Stimulasi adalah kegiatan yang dilakukan untuk merangsang kemampuan dasar anak agar dapat tumbuh dan berkembang secara optimal. Setiap anak perlu mendapatkan stimulasi rutin yang diberikan oleh orang tua serta anggota keluarga lain dan kelompok masyarakat di lingkungan rumah tempat tinggal anak (KEMENKES RI, 2010).

Perkembangan motorik halus merupakan satu tahap perkembangan yang akan dilalui seorang anak. Motorik halus merupakan aspek yang berhubungan dengan kemampuan anak untuk melakukan gerakan yang melibatkan otot-otot tubuh yang kecil dengan koordinasi yang baik (Kyle \& Carman, 2013). Keterlambatan perkembangan motorik dapat disebabkan karena kurangnya stimulasi yang diberikan orang tua sehingga anak tidak mendapatkan kesempatan untuk mempelajari keterampilan motorik. Peran orang tua sangat besar, maka pengetahuan orang tua tentang stimulasi dan perkembangan motorik halus anak sangat diperlukan (Bowden \& Greenberg, 2010).

Kemampuan motorik halus anak yang baik dapat membantu anak agar anak dapat menyesuaikan dengan lingkungan sosial, meningkatkan kemampuan diri untuk kordinasi mata dan tangan secara optimal, sehingga memungkinkan anak melakukan kegiatan sendiri untuk melatih rasa kepercayaan diri (Kyle \& Carman, 2013).

Penelitian yang dilakukan Cahyanigrum (2013) didapati bahwa terdapat hubungan antara pengetahuan ibu tentang stimulasi dengan perkembangan anak usia 3-5 tahun di kelurahan Kranggan Temanggung. Selanjutnya, penelitian Fauziyah (2016) juga menyatakan bahwa terdapat hubungan yang signifikan antara pengetahuan ibu tentang stimulasi dan perkembangan motorik halus anak usia 4-5 tahun dengan arah korelasi positif.

Hasil penelitian Siliwir (2017) yang dilakukan di TK Unklab, dari 24 responden penelitian terdapat 20 anak berada pada kategori perkembangan motorik halus dicurigai, sehingga berdasarkan latar belakang inilah, maka peneliti tertarik untuk melakukan penelitian mengenai hubungan pengetahuan orang tua tentang 
stimulasi dan perkembangan motorik halus anak pra sekolah.

\section{BAHAN DAN METODE}

Metode yang digunakan dalam penelitian ini adalah deskriptif korelasi dengan pendekatan Cross-sectional, yaitu jenis penelitian yang menekankan waktu pengukuran data variabel independen dan dependen hanya satu kali pada satu saat (Nursalam, 2009). Variabel dependen pada penelitian ini adalah perkembangan motorik halus anak pra sekolah dan variabel independen adalah pengetahuan orang tua tentang stimulasi. Hipotesis penelitian ini adalah $\mathrm{Ha}$ ada hubungan pengetahuan orang tua tentang stimulasi dengan perkembangan motorik halus anak pra sekolah di TK Unklab.

Populasi dalam penelitian ini adalah orang tua (ayah atau ibu) dan anak-anak TK Unklab dan TK Mitra masyarakat Airmadidi yang berjumlah 55 orang tua dan 55 anak. Teknik pengambilan sampel yang digunakan adalah purposive sampling dimana sampel yang diambil dalam penelitian ini adalah sampel yang memenuhi kriteria yang ditetapkan peneliti. Adapun kriteria inklusi pada penelitian ini adalah orang tua (ayah atau ibu) yang mengantar anak usia 4-5 tahun, anak aktif bersekolah dan bersedia untuk menjadi responden dalam penelitian. Jumlah sampel pada penelitian ini adalah 46 orang. Pengumpulan data dilakukan dengan kuesioner dan lembar observasi KPSP. Instrumen untuk mengukur variabel independen yaitu pengetahuan orang tua menggunakan kuesioner dengan 10 pernyataan, terdiri dari 8 pernyataan positif dan 2 pernyataan negatif dengan pilihan jawaban benar atau salah. Interpretasi jawaban kuesioner pengetahuan baik bila responden dapat menjawab 76-100\%, cukup bila responden dapat menjawab 56$75 \%$ dan kurang bila responden menjawab $<56 \%$ dari total jawaban pertanyaan. Selanjutnya untuk mengukur perkembangan motorik halus anak menggunakan lembar observasi berdasarkan
Kuesioner Pra Skrining Perkembangan (KPSP), interpretasi jawaban kuesioner apabila terdapat 8-9 jawaban YA perkembangan anak sesuai (S), 6-7 jawaban YA perkembangan anak meragukan (M) dan $<6$ jawaban YA kemungkinan mengalami penyimpangan (P). Untuk menganalisis hubungan antara variabel, uji statistic yang digunakan dalam penelitian ini adalah Uji spearman rank dengan tingkat kepercayaan $95 \%$ dan derajat kesalahan $5 \%$.

\section{HASIL DAN PEMBAHASAN}

Hasil penelitian mengenai gambaran pengetahuan orang tua tentang stimulasi dilakukan melalui pengumpulan data menggunakan kuesioner. Gambaran pengetahuan tersebut dapat dilihat pada tabel 1.

Berdasarkan tabel 1 dapat diketahui bahwa responden dengan pengetahuan tentang stimulasi baik sejumlah 45 $(97,8 \%)$, pengetahuan cukup sejumlah 1 $(2,2 \%)$ dan tidak terdapat responden yang memiliki pengetahuan yang kurang tentang stimulasi pada anak pra sekolah. Dapat disimpulkan bahwa sebagian besar orang tua memiliki pengetahuan yang baik tentang stimulasi pada anak khususnya anak usia pra sekolah.

Pengetahuan merupakan hasil dari tahu dan ini terjadi setelah seseorang melakukan pengindraan terhadap objek tertentu, dalam hal ini proses pengindraan terjadi melalui pancaindra manusia. Sebagian besar pengetahuan manusia diperoleh melalui penglihatan dan pendengaran, sehingga pengetahuan merupakan domain yang sangat penting dalam membentuk tindakan seseorang (Efendi \& Makhfudli, 2009).

Berdasarkan wawancara langsung peneliti dengan responden penelitian, bahwa orang tua mengetahui tentang pentingnya stimulasi pada anak, berdasarkan informasi yang didapatkan dari media masa maupun elektronik. Menurut Aritonang (2012) dengan pengasuhan yang dilakukan orang tua kepada anak, dapat 
membantu meningkatkan pengetahuan ibu mengenai pertumbuhan dan perkembangan anak, sehingga dapat mempengaruhi kesiapan ibu dalam memberikan stimulasi bagi anak, oleh karena itu seorang ibu perlu mencari informasi tentang perkembangan anak.

Hasil penelitian mengenai gambaran perkembangan motorik halus anak dilakukan melalui pengumpulan data menggunakan kuesioner. Gambaran perkembangan motorik halus tersebut dapat dilihat pada tabel 2 .

Berdasarkan tabel 2 dapat diketahui distribusi perkembangan motorik halus anak prasekolah yaitu yang sesuai usia sejumlah $11(23,9 \%)$, meragukan sejumlah $30(65,2 \%)$ dan sejumlah $5(10,9 \%)$ anak mengalami penyimpangan perkembangan motorik halus. Sehingga dapat disimpulkan sebagian besar perkembangan motorik halus anak pra sekolah berada pada kategori meragukan.

Menurut Notoatmodjo (2012) perilaku merupakan respon dari individu akibat dari adanya stimulus atau rangsangan dari luar. Perkembangan seorang anak dipengaruhi oleh banyak faktor antara lain lingkungan tempat tinggal, pengalaman belajar, budaya dan cara pengasuhan yang dilakukan oleh orang tua (Potts \& Mandleco, 2012).

Menurut Kementrian Kesehatan (2010) terdapat faktor internal dan eksternal yang dapat mempengaruhi kualitas tumbuh kembang seorang anak. Faktor internal antara lain ras, keluarga, umur, jenis kelamin, genetik. Sedangkan yang menjadi faktor eksternal adalah gizi, infeksi, psikologi, sosial ekonomi dan stimulasi.

Menurut Brito, Engle \& Super (2013) efek negatif dari status sosial ekonomi yang rendah dapat menyebabkan status pengasuhan dan lingkungan yang kurang menunjang untuk memberikan stimulasi bagi anak. Untuk menunjang perkembangan anak sangat diperlukan rangsangan atau stimulasi khususnya dari keluarga, misalnya dengan menyediakan alat permainan, sosialisasi anak dan keterlibatan ibu dan semua anggota keluarga dalam setiap kegiatan anak.

Pada tabel 3 dapat diketahui hasil analisis hubungan pengetahuan orang tua tentang stimulasi dengan perkembangan motorik halus anak pra sekolah. Hasil analisis menunjukkan bahwa $11(24,4 \%)$ orang tua memiliki pengetahuan yang baik tentang stimulasi dan anaknya memiliki perkembangan motorik halus yang sesuai usia, $30(66,7 \%)$ orang tua memiliki pengetahuan baik dan anaknya memiliki perkembangan motorik meragukan dan 4 $(8,9 \%)$ orang tua memiliki pengetahuan baik dan anaknya memiliki penyimpangan perkembangan motorik halus. Untuk kategori selanjutnya dapat diketahui bahwa hanya $1(20 \%)$ orang tua yang memiliki pengetahuan yang cukup tentang stimulasi dan anaknya memiliki penyimpangan perkembangan motorik halus.

Hasil uji statistik untuk menguji hubungan pengetahuan orang tua tentang stimulasi dengan perkembangan motorik halus anak pra sekolah, diperoleh nilai signifikan $p$ value $=0,06>0,05$. Hasil ini menunjukkan penolakan pada pernyataan Ha: terdapat hubungan signifikan pengetahuan orang tua tentang stimulasi dengan perkembangan motorik halus anak pra sekolah.

Pengetahuan orang tua akan stimulasi sangat penting untuk menunjang perkembangan anak pra sekolah. Namun pada penelitian Bornstein, Putnick, Lansford, Deater-Deckard \& Bradley (2015) menyatakan bahwa sangat diperlukan keterlibatan langsung orang tua dalam melakukan stimulasi khususnya dalam aktivitas bermain dengan anak. Lebih lanjut Knauer, Ozer, Dow \& Fernald, (2018) menyebutkan bahwa diperlukan kualitas pengasuhan yang responsif dan penuh kehangatan dari orang tua untuk menunjang perkembangan anak, khususnya anak usia pra sekolah.

Pada penelitian ini didapati bahwa sebagian besar orang tua 45(97,8\%) memiliki pengetahuan yang baik mengenai stimulasi, tetapi dari segi perkembangan 
motorik halus anak didapati bahwa sebagian besar anak 30 $65,2 \%)$ berada pada kategori meragukan pada perkembangan motorik halus. Hasil ini menunjukkan bahwa sangat kurang keterlibatan orang tua dalam memberikan stimulasi. Pengetahuan yang baik tentang stimulasi perkembangan bila tidak didukung oleh perilaku atau tindakan dapat menyebabkan pengetahuan yang dimiliki menjadi tidak bermanfaat.

Menurut Kariger, Frongillo, Engle, Britto, Sywulka \& Menon (2012) kualitas pengasuhan harus berdasarkan Family Care Indicators (FCI) yaitu dengan menyediakan permainan yang bervariasi seperti bermain musik, menggambar, menyusun balok, buku bergambar dan belajar membedakan bentuk dan warna. Lebih lanjut Kariger dkk (2012) menyatakan bahwa dalam FCI harus melibatkan aktivitas bermain yang dilakukan orang tua bersama-sama anak yaitu bernyanyi, bercerita dongeng, mengajak anak keluar rumah dan orang tua harus meluangkan waktu untuk mengajari anak belajar menghitung dan mempelajari nama-nama benda di lingkungan sekitar

\section{KESIMPULAN DAN SARAN}

Berdasarkan pembahasan yang telah dijelaskan sebelumnya bahwa dari hasil penelitian tentang "Hubungan pengetahuan orang tua tentang stimulasi dengan perkembangan motorik halus anak pra sekolah, maka dapat disimpulkan sebagai berikut:

1. Distribusi frekuensi pengetahuan orang tua tentang stimulasi, sebagian besar berada pada kategori baik 45(97,8\%).

2. Distribusi frekuensi perkembangan motorik halus anak pra sekolah, sebagian besar berada pada kategori meragukan $30(65,2 \%)$.

3. Tidak terdapat hubungan yang signifikan pengetahuan orang tua tentang stimulasi dengan perkembangan motorik halus anak pra sekolah dengan $p$ value $0,06>0,05$.
Sebagai saran bagi tenaga kesehatan agar dapat melakukan penyuluhan kepada masyarakat mengenai pentingnya melakukan stimulasi untuk membantu meningkatkan keterlibatan keluarga khususnya orang tua dalam memberikan stimulasi untuk perkembangan kemampuan motorik halus anak, dengan menyediakan permainan yang sesuai usia anak dan terlibat langsung dalam kegiatan bermain.

Orang tua diharapkan untuk selalu memantau perkembangan anak serta melatih anak dalam melakukan aktivitas yang sesuai dengan usia, supaya anak dapat terhindar dari penyimpangan perkembangan. Untuk peneliti selanjutnya diharapkan menambah jumlah sampel dan menambahkan variabel usia, pekerjaan orangtua, sosial ekonomi, latar belakang budaya.

\section{DAFTAR PUSTAKA}

Aritonang, T.R. (2012). Hubungan pengetahuan orang tua tentang stimulasi motorik kasar dengan perkembangan motorik kasar anak prasekolah di TK Nusa Indah Bekasi. Diakses dari: https://ayurvedamedistra.files.wordp ress.com

Bornstein, M. H., Putnick, D. L., Lansford, J. E., Deater-Deckard, K., \& Bradley, R. H. (2015). A developmental analysis of caregiving modalities across infancy in 38 lowand middle-income countries. Child Development, 86(5), 1571-1587.

Bowden, V.R \& Greenberg, C.S. (2010). Children and their families: the continuum of care. Philadelphia: Lippincott Williams \& Wilkins. 
Brito, P.R., Engle, P.L \& Super, C.M. (2013). Handbook of early childhood development research and its impact on global policy. Oxford University Press.

Cahyanigrum,M. (2013). Hubungan antara pengetahuan ibu tentang stimulasi dengan tingkat perkembangan pada anak usia 3-5 tahun di kelurahan Kranggan Temanggung. Diakses dari: digilib.unisayogya.ac.id

Effendi, F \& Makhfudli. 2009.

Keperawatan Kesehatan Komunitas: Teori dan Praktek Dalam Keperawatan. Jakarta: Salemba medika.

Fauziyah, A. N. (2016). Hubungan pengetahuan ibu tentang stimulasi dan perkembangan motorik halus pada anak usia 4-5 tahun. Diakses dari: https://digilib.uns.ac.id

Kariger, P., Frongillo, E.A., Engle, P., Britto., P., Sywulka,S.M \& Menon, P. (2012). Indicators of family care for development for use in multicountry surveys. Journal of health, population, and nutrition. 30(4). 472-486
Kementrian kesehatan R.I. (2010). Pedoman pelaksanaan stimulasi, deteksi dan intervensi dini tumbuh kembang anak ditingkat kesehatan dasar. Jakarta.

Knauer, H. A., Ozer, E.J., Dow, W.H \& Fernald, L.C.H. (2018). Parenting quality at two developmental periods in early childhood and their association with child development. Early Childhood Research Quarterly. Article in press. Xxx (2018) $\mathrm{xxx}-$ xxx. 1-9.

Kyle, Terri., \& Carman, Susan. (2014). Buku ajar keperawatan pediatric. Edisi 2. Jakarta : Buku Kedokteran EGC.

Nursalam. (2009). Metodologi penelitian ilmu keperawatan. Jakarta: Salemba Medika

Potts, N.L \& Mandleco, B.L. (2012). Pediatric nursing: Caring for children and their families, Third Edition. USA: Delmar.

Siliwir, S. (2017). Pengaruh permainan edukatif puzzle terhadap perkembangan motorik halus anak usia prasekolah di TK UNKLAB. Skripsi 
Tabel 1. Distribusi Frekuensi Pengetahuan Orang tua Tentang Stimulasi

\begin{tabular}{lll}
\hline Pengetahuan & Frekuensi & $\begin{array}{l}\text { Persentasi } \\
(\%)\end{array}$ \\
\hline Baik & 45 & 97,8 \\
\hline Cukup & 1 & 2,2 \\
\hline Kurang & 0 & 0
\end{tabular}

Tabel 2. Distribusi Frekuensi Perkembangan Motorik Halus Anak

\begin{tabular}{lll}
$\begin{array}{l}\text { Perkembangan } \\
\text { Motorik Halus }\end{array}$ & Frekuensi & $\begin{array}{c}\text { Presentasi } \\
(\boldsymbol{\%})\end{array}$ \\
\hline Sesuai & 11 & 23,9 \\
\hline Meragukan & 30 & 65,2 \\
\hline Penyimpangan & 5 & 10,9 \\
\hline
\end{tabular}

Tabel 3. Distribusi Frekuensi Hubungan Pengetahuan Orang Tua Tentang Stimulasi Dengan Perkembangan Motorik Halus Anak

\begin{tabular}{|c|c|c|c|c|c|c|}
\hline \multirow{2}{*}{$\begin{array}{l}\text { Pengetahuan } \\
\text { Orang tua }\end{array}$} & \multicolumn{3}{|c|}{ Perkembangan Motorik Halus } & \multirow[b]{2}{*}{ Total } & \multirow[b]{2}{*}{$\begin{array}{l}\text { Coefficient } \\
\text { correlation }\end{array}$} & \multirow[b]{2}{*}{$p$ value } \\
\hline & $\begin{array}{l}\text { Sesuai } \\
\text { (f) } \quad(\%)\end{array}$ & $\begin{array}{l}\text { Meragukan } \\
\text { (f) }(\%)\end{array}$ & $\begin{array}{l}\text { Penyimpangan } \\
\text { (f) }(\%)\end{array}$ & & & \\
\hline Baik & $11(23,9)$ & $30(65,2)$ & $4(8,6)$ & 97,7 & \multirow{3}{*}{0,274} & \multirow{3}{*}{0,06} \\
\hline Cukup & 0 & 0 & $1(2,3)$ & 2,3 & & \\
\hline Total & $11(23,9)$ & $30(65,2)$ & $5(10,9)$ & 100 & & \\
\hline
\end{tabular}

